J. Lake Sci.(湖泊科学), 2019, 31(1): 183-194

DOI 10. 18307/2019. 0117

(c) 2019 by Journal of Lake Sciences

\title{
鄱阳湖枯水期延长背景下越冬水鸟群落结构、丰富度及其空间分布 格局”
}

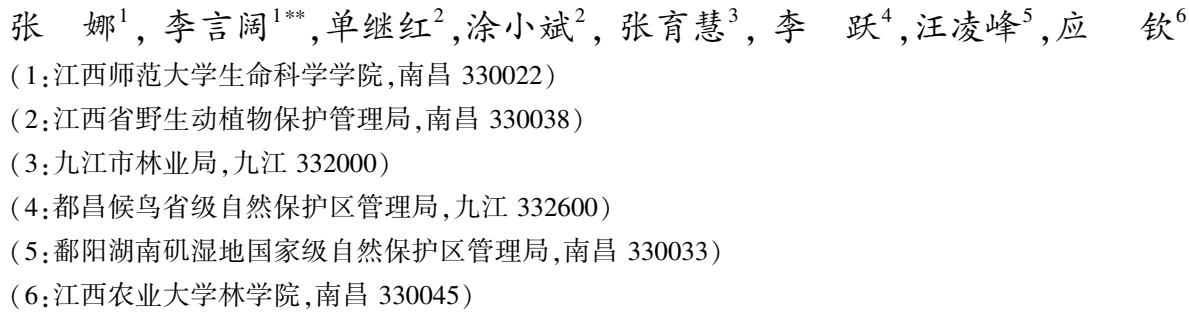

摘 要: 鄱阳湖是我国最大的淡水湖,也是具有国际意义的候鸟越冬地. 本研究于 2015 和 2016 年越冬期对鄱阳湖越冬 水鸟的群落结构、丰富度和空间分布进行了系统的调查, 分别记录到水鸟 494033 和 388017 只, 隶属于 6 目 13 科 68 种. 雁形目和鸭形目鸟类种类最多,其次是鹳形目和鹤形目; 从生态型来看, 游禽 32 种, 涉禽 36 种. 雁鸭类相对丰富度最高, 是鄱阳湖越冬水鸟的优势类群,其次是鸭形目鸟类,而 2015 和 2016 年鹤形目鸟类数量仅占当年总数量的 $2.6 \%$ 和 $1.4 \%$. 在鄱阳湖湿地的不同区域, 越冬水鸟种类组成差异较大. 从空间分布来看,越冬水鸟主要集中在鄱阳湖自然保护区、九江 湿地和南昌湿地. 开展鄱阳湖越冬水鸟的种群数量调查, 摸清越冬水鸟群落结构和种群丰富度现状, 对于有针对性地开 展越冬水鸟保护具有重要意义.

关键词: 鄱阳湖; 越冬水鸟; 丰富度;多样性;分布

\section{Community structure, abundance and spatial distribution of water birds wintering in Poy- ang Lake wetland}

ZHANG $\mathrm{Na}^{1}$, LI Yankuo ${ }^{1 * *}$, SHAN Jihong ${ }^{2}$, TU Xiaobin ${ }^{2}$, ZHANG Yuhui ${ }^{3}$, LI Yue ${ }^{4}$, WANG Lingfeng ${ }^{5}$ \& YING Qin ${ }^{6}$

(1: College of Life Sciences, Jiangxi Normal University, Nanchang 330022, P.R. China)

(2: Jiangxi Wildlife Service, Nanchang 330038, P.R.China)

(3: Jiujiang Forestry, Jiujiang 332000, P.R.China)

(4: Duchang Provincal Migratory Bird Nature Reserve, Jiujiang 332600, P.R.China)

(5: Nanji National Nature Reserve of Poyang Lake, Nanchang 330033, P.R.China)

(6: College of Forestry, Jiangxi Agricultural University, Nanchang 330045, P.R.China)

Abstract: Poyang Lake is the largest freshwater lake in China and an internationally important wintering ground for water birds. In this study, the water bird community structure, abundance and spatial distribution are systematically investigated. The survey covers the whole area of Poyang Lake and records a total of 68 species of water birds belonging to 13 families from 6 orders. In total, 494033 and 388017 individuals were observed in winter of 2015 and 2016. Water birds of Anseriformes and Charadriiformes were the most abundant in species number, followed by Ciconiiformes and Gruiformes. There were 32 waterfowl species, and 36 shorebirds. As for relative abundance, Anatidae was the most abundant and thus the dominant group. followed by Charadriiformes. While Gruiformes only accounted for about $2.6 \%$ and $1.4 \%$ in 2015 and 2016. Meanwhile, evident spatial variations of water bird abun-

* 国家自然科学基金项目 (31660618,31460107) 和江西省水利厅科技项目(KT201436) 联合资助. 2018-02-22 收稿; 2018-06-04 收修改稿. 张娜 (1995 ), 女, 硕士研究生; E-mail: 2579164614@ qq.com.

** 通信作者; E-mail: liyankuo@ 126.com. 
dance and species composition were found in Poyang Lake. Therefore, it is of great significance to find out the current status of wintering water birds in Poyang Lake for scientific decision-making on water bird conservation.

Keywords: Poyang Lake; wintering water birds; abundance; bird diversity; distribution

鄱阳湖地处长江南岸, 江西省北部, 面积广阔, 是我国最大的淡水湖, 也是全球重要的水鸟越冬地, 在世 界生物多样性保护上有着极为重要的意义 ${ }^{[1-2]}$. 在鄱阳湖越冬的水鸟最多纪录超过 50 万只, 是白鹤 ( Grus leucogeranus)、白头鹤 (G. monacha)、白枕鹤 (G. vipio)、东方白鹳 (Ciconia boyciana) 、小天鹅 (Cygnus columbianus $)$ 等珍稀濒危鸟类的重要越冬地, 世界上约 $99 \%$ 的白鹤和 $80 \%$ 以上的东方白鹳在此越冬 ${ }^{[3]}$. 作为全球重 要的水鸟越冬地, 鄱阳湖湿地生态环境直接关系到区域水鸟的越冬安全, 影响着其全球种群的恢复和发展. 因此, 开展鄱阳湖越冬水鸟的种群数量调查, 摸清越冬水鸟群落结构和种群丰富度现状对于掌握长江流域 乃至全球水鸟种群动态具有重要的意义 ${ }^{[4]}$.

1980s 以来, 鄱阳湖区生物多样性受到越来越多的关注, 鸟类物种多样性和群落结构一直是鄱阳湖区生 物多样性保护研究的热点. 大量的研究报道了鄱阳湖湿地鸟类多样性 ${ }^{[5-7]}$, 但是由于鄱阳湖湿地面积大、湖 泊众多,导致绝大多数鸟类多样性研究集中在鄱阳湖局部地区,如鄱阳湖国家级自然保护区、鄱阳湖南矶湿 地国家级自然保护区、都昌候鸟省级自然保护区 ${ }^{[8-9]}$. 小尺度上的鸟类调查虽然能够部分反映鄱阳湖湿地的 鸟类群落特征, 但是无法揭示整个鄱阳湖湿地的鸟类资源状况, 也无法为管理部门从较大的尺度上制定科 学的候鸟保护管理对策提供精准的科学依据.

近年来受气候变化和长江上游水利工程的影响, 鄱阳湖水位情势发生了明显改变, 尤其表现为枯水期 提前, 冬季水位持续偏低 ${ }^{[10]}$, 对鄱阳湖湿地的一系列生态过程产生了显著的影响. 有学者对此进行研究发 现, 自 2003 年三峡大坝蓄水运行后, 鄱阳湖全年的月平均水位均低于运行前 ${ }^{[11]}$, 湿地的过早露出, 直接决定 了越冬水鸟对食物和栖息地的可获得性, 虽然这种可获得性在一定程度上取决于不同水鸟获得食物的能 力, 但是过低水位造成的岸线长度减少、植物资源的过早萌芽, 会严重影响水鸟栖息地的分布, 导致越冬水 鸟生存质量下降.

因此, 为了进一步掌握鄱阳湖区水文情势变化下越冬水鸟资源现状, 我们分别在 2015 年和 2016 年越冬 期对鄱阳湖区越冬水鸟进行了系统调查, 旨在摸清鄱阳湖区越冬水鸟资源现状, 掌握鄱阳湖湿地生态环境 改变背景下越冬水鸟的丰富度、物种多样性以及空间分布, 为鄱阳湖区越冬水鸟的保护和管理提供科学 依据.

\section{1 研究区域概况}

鄱阳湖 $\left(28^{\circ} 22^{\prime} \sim 29^{\circ} 45^{\prime} \mathrm{N}, 115^{\circ} 47^{\prime} \sim 116^{\circ} 45^{\prime} \mathrm{E}\right.$ ) 是我国最大的淡水湖泊, 流域面积 $16.2 \times 10^{4} \mathrm{~km}^{2}$, 位于长 江中下游南岸, 江西北部. 该区属亚热带湿润季风型气候, 气温季节性变化明显, 年平均气温 $17.6^{\circ} \mathrm{C}$, 年降水 量 $1450 \sim 1550 \mathrm{~mm}$. 鄱阳湖湿地分布有丰富的鸟类资源, 迄今共记录鸟类 352 种, 隶属 17 目 61 科, 其中水鸟 6 目 16 科 133 种,占中国水鸟种数的 $49 \%$; 世界自然保护联盟 (IUCN) 受胁鸟类 16 种, 国家 I 级保护鸟类 9 种, 国家 II 级保护鸟类 49 种,包括白鹤、青头潜鸭 (Aythya baeri)、东方白鹳、中华秋沙鸭 (Mergus squamatus) 等. 在居留型方面, 冬候鸟 130 种, 留鸟 99 种, 夏候鸟 62 种, 旅鸟 52 种, 迷鸟 9 种. 鄱阳湖区目前共建立以候 鸟及湿地生态系统保护为主要保护对象的保护区 18 个, 总面积达 $2006.18 \mathrm{~km}^{2}$, 已经构建了相对完善的鄱阳 湖越冬水鸟就地保护网络 ${ }^{[12]}$.

鄱阳湖是一个季节性吞吐型湖泊,承接江西五大水系 (赣江、抚河、信江、饶河、修水) 的来水, 同时水位 也受到长江来水的影响, 长江来水时有倒灌人湖的现象. 水位年变幅达 $9.79 \mathrm{~m}, 4$ 月进人汛期, 呈湖相, 7 月 达最高水位, 11 月进入枯水期, 持续到翌年 3 月, 表现为独特的湿地景观 ${ }^{[13]}$. 丰、枯水期的鄱阳湖水域面积、 水容积相差极大, “高水是湖, 低水似河, 丰水一片, 枯水一线” 是鄱阳湖区的自然地理特征. 但受三峡工程的 影响, 鄱阳湖水文动态发生改变, 自 2010 年以来水位发生了明显的变化, 2010-2016 年枯水期提前, 水位下 降速度增大, 同时丰水期水位增高, 高水位持续时间增长(图 1), 这对鄱阳湖越冬水鸟的栖息生存将产生消 极效应. 


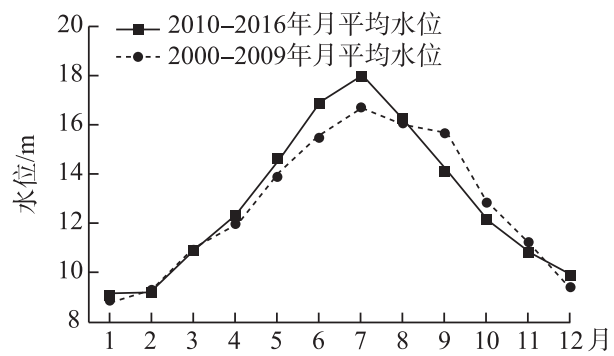

图 1 鄱阳湖 2000-2016 年月平均水位

Fig.1 Average water level of Poyang Lake during the period of 2000-2016

\section{2 研究方法}

\section{1 水鸟调查}

本研究分别于 2015 年 12 月 26 日和 2017 年 1 月 17 日采用样线法开展鄱阳湖越冬期水鸟同步调查,均 在当天上午 9 点开始, 调查区域跨度为整个鄱阳湖区 (图 2), 包括鄱阳湖区 3 市 13 县(市、区) 境内所有主要 湖泊 (表 1). 根据湖泊的空间分布,将调查地区划分为 5 个片区: 鄱阳湖国家级自然保护区、南矶湿地国家 级自然保护区、九江市鄱阳湖区湿地 (简称九江湿地)、南昌市鄱阳湖区湿地 (简称南昌湿地) 和上饶市鄱阳 湖区湿地(简称上饶湿地).

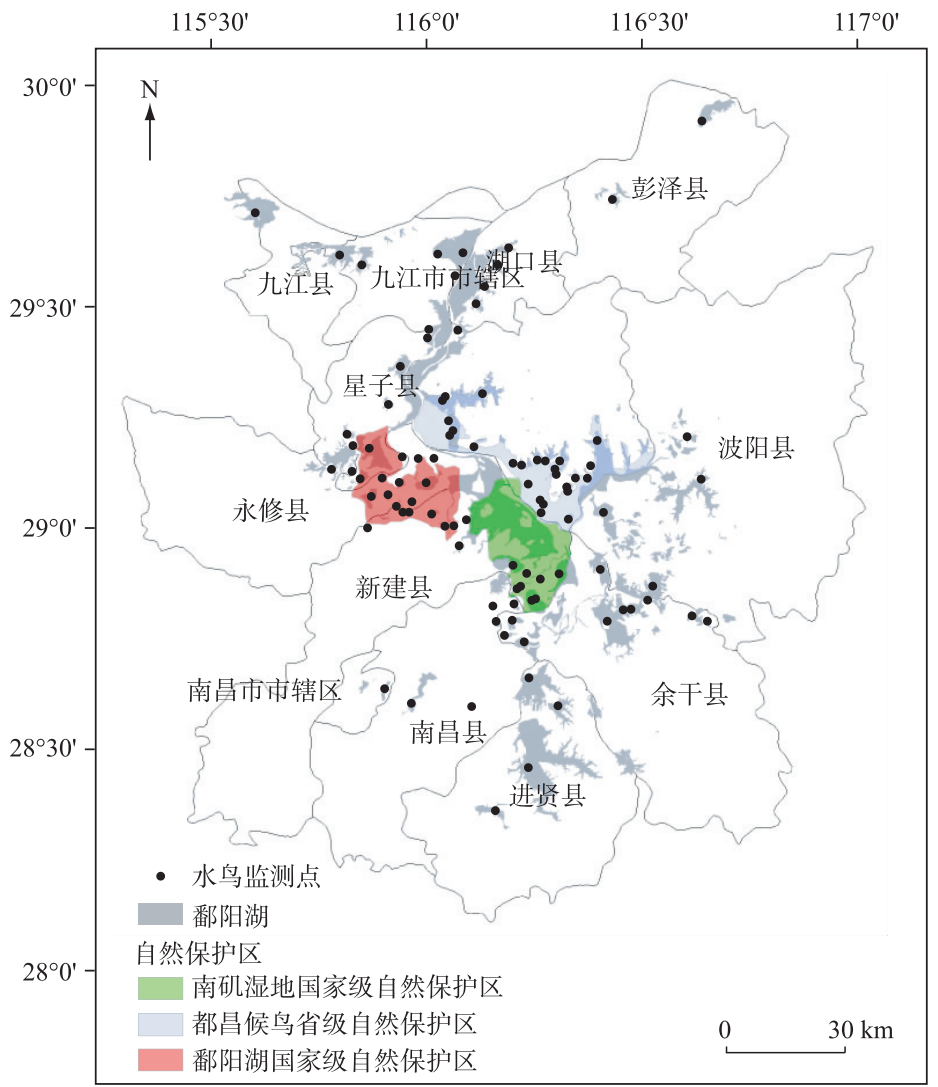

图 2 研究地区和水鸟调查湖泊位置

Fig. 2 Study area and the locations of water bird surveys 
根据子湖数量, 设计了 41 条样线, 每个调查组负责 $1 \sim 3$ 个样线, 每组人员至少包括 1 名专业人员和 1 名当地野生动物保护管理站的工作人员. 每组配备 1 台单筒望远镜 $(20 \sim 60) 、 1$ 台双筒望远镜 $(8 \times 42) 、 G P S$ 和相机等工具. 调查主要采用环湖步行或乘船的方式开展, 发现水鸟后以单筒望远镜确认鸟种并计数, 将无 法鉴定的物种归人未识别种类. 在计数时, 对数量较小的群体 (包括鹤类和鹳形目鸟类) 采取直接计数法, 而 对集群较大、数量较多的种类 (包括鸿雁、豆雁、灰雁、白额雁和微形目鸟类等), 将大的集群分为 $20 、 50$ 或 100 的小群体分别计数. 在调查中由于距离太远而不能识别的鸟类, 则按照生态类群进行统计, 例如: “鸭 类”、“雁类”、“鸢敄类”等.

本研究鸟类分类体系参考郑光美《中国鸟类分类与分布名录》 (第 2 版 $)^{[14]}$. 查阅相关的参考资料 ${ }^{[15-16]}$, 确定鸟类居留型、生态型和保护级别. 本研究依据《湿地公约》中的定义, 将鹗鹤目、鹳形目、雁形目、鹆形目、 鹈形目 (鹈胡科、扸鹚科) 和鹤形目 (鹤科、秧鸡科) 划分为水鸟.

表 1 调查湖区

Tab.1 Survey sites

\begin{tabular}{|c|c|c|}
\hline 地区 & 县( 区、市) & 湖区 \\
\hline 鄱阳湖国家级自然保护区 & 星子县 & $\begin{array}{l}\text { 大湖池、朱市湖、常湖池、象湖、中湖池、大汉湖、董家湖、梅西湖、小滩湖、 } \\
\text { 苍湖、茶湖、蚌湖、沙湖、长湖、寺下湖、邓湖、蟇豆湖、州边湖 }\end{array}$ \\
\hline 南矶湿地国家级自然保护区 & 新建县 & $\begin{array}{l}\text { 上北甲湖、涧塘湖、下北甲湖、神塘湖、红兴湖、三泥湾、战备湖、白沙湖、 } \\
\text { 常湖、凤尾湖、北深湖、上茶湖、中茶湖、下茶湖、上段湖、曾备湖、男深湖、 } \\
\text { 赣江尾问、草皮角湖、珠湖、东湖口、太子河道、饭湖、泥湖、神宕湖、人参 } \\
\text { 湖、赣江中支、东江湖 }\end{array}$ \\
\hline \multirow[t]{8}{*}{ 九江湿地 } & 都昌县 & $\begin{array}{l}\text { 马影湖、千字湖、矶山湖、黄金嘴、南溪湖、龙潭湖、输湖、竹筒湖、焦潭湖、 } \\
\text { 石牌湖、新妙湖、大泟池、小泟池、香阳圩堤、十里湖、沙港、范垄、老爷庙、 } \\
\text { 西湖、泥坑湖、宋家汊、钱公桥湖、泊水湖、高桥湖、下坝湖、花庙湖、火山 } \\
\text { 垅湖、江畔湖、盘湖 }\end{array}$ \\
\hline & 湖口县 & 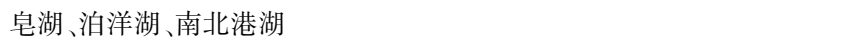 \\
\hline & 共青城 & 南湖 \\
\hline & 彭泽县 & 太白湖、芳湖 \\
\hline & 瑞昌区 & 赤湖 \\
\hline & 九江县 & 赛城湖、东湖、赤湖、里湖、谷山湖、团湖 \\
\hline & 庐山区 & 鞋山湖、谷山湖、七里湖 \\
\hline & 星子县 & 梅溪湖、十里湖、蓼花池 \\
\hline 南昌湿地 & 南昌市 & 瑶湖、三湖 \\
\hline & 进贤县 & 青岗湖、金溪湖、坎下湖、陈家湖、军山湖 \\
\hline 上饶湿地 & $\begin{array}{l}\text { 余干县 } \\
\text { 鄱阳县 }\end{array}$ & $\begin{array}{l}\text { 插旗洲、润溪湖、前湖、康山大堤、大湖口、东湖、林充湖、南山湖、程家池 } \\
\text { 大小莲子湖、汉池湖、大鸣湖、茶湖、企湖 }\end{array}$ \\
\hline
\end{tabular}

\section{2 数据分析}

利用 Shannon-Wiener 多样性指数、Simpson 优势集中性指数、Peilou 均匀性指数分析鄱阳湖区鸟类群落 特征.

鸟类群落多样性采用 Shannon-Wiener 多样性指数计算, 公式为:

$$
H^{\prime}=-\sum\left(P_{i}\right)\left(\log _{2} P_{i}\right)
$$

群落优势度指数采用 Simpson 优势度指数计算, 公式为:

$$
D=1-\sum P_{i}^{2}
$$

式中, $H^{\prime}$ 为多样性指数, $D$ 为 Simpson 优势度指数, $P_{i}$ 表示物种 $i$ 的个体在所有物种个体总数中的比例.

均匀性的测度采用 Peilou 均匀性指数计算, 公式为:

$$
\begin{aligned}
& J=H^{\prime} / H_{\max } \\
& H_{\text {max }}=\log _{2} S
\end{aligned}
$$


式中, $J$ 为 Pielou 均匀性指数, $H_{\max }$ 为多样性的最大值, $S$ 为物种数.

\section{3 结果}

\section{1 水鸟种类组成}

2015 年和 2016 年冬季共记录水鸟 68 种,隶属 6 目 13 科 (表 2). 其中, 2015 年冬季记录水鸟 50 种, 494033 只, 可识别水鸟 419210 只, 占总数的 $84.9 \%$, 未识别到种的个体 74823 只, 占 $15.1 \%$; 2016 年冬季记录 63 种水鸟, 388017 只, 可识别水鸟数量 297251 只,占总数的 $76.6 \%$, 未识别个体 90766 只, 占 $23.4 \%$. 未识别 水鸟主要是雁鸭类和微璚类物种. 在 68 种水鸟中,绿鹭 (Butorides striatus)、棉向 (Nettapus coromandelianus)、

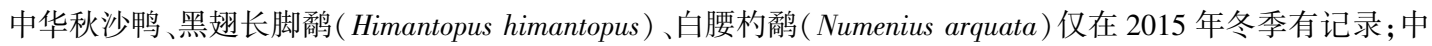
白路 (Egretta intermedia) 、夜路 ( Nycticorax nycticorax)、黑脸琵路 (Platalea minor)、小白额雁 (Anser erythropus)、黑雁( Branta beernicla)、赤膀鸭 (Anas strepera)、青头潜鸭、普通秋沙鸭 (Mergus merganser)、斑头 秋沙鸭 (Mergellus albellus)、普通秧鸡 (Rallus aquaticus)、红脚苦恶鸟 (Amaurornis akool)、灰头麦鸡 (Vanellus

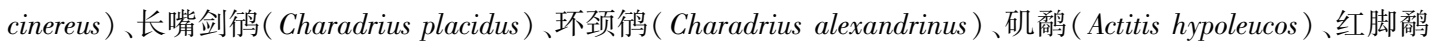
(Tringa totanus)、林璚 ( T. glareola)、针尾沙雉(Gallinago stenura)、扇尾沙雉 (G. gallinago) 仅在 2016 年冬季 有记录. 具体见表 2.

从物种组成来看, 雁形目和鸥形目鸟类种类最多, 雁形目鸟类 1 科 25 种, 主要是雁鸭类物种; 鸺形目鸟 类 5 科 23 种,包括反嘴璚科、鸭科、部科、鸥科、燕鸥科. 其次是鹳形目鸟类, 3 科 9 种,包括路科、鹳科、噮科;

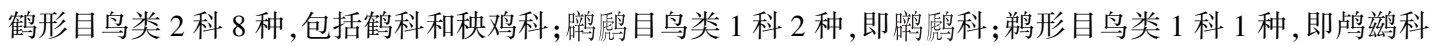
(表 2). 从生态型看, 游禽 4 目 5 科 32 种,包括扸讹目、鹈形目、雁形目、鸥科、燕鸥科; 涉禽类 3 目 8 科 36 种,包括鹳形目、鹤形目、微形目 (除鸥科、燕鸥科外).

在地理区系构成上, 该区鸟类组成具有明显的古北界特征, 古北界种类达 53 种, 占总数的 $77.9 \%$; 东洋 界种类共 7 种,占总数的 $10.3 \%$; 广布种 8 种,占总数的 $11.8 \%$. 在居留型方面, 冬候鸟 46 种,夏候鸟 10 种, 留鸟 4 种, 旅鸟 7 种, 迷鸟 1 种, 分别占水鸟种类的 $67.6 \% 、 14.7 \% 、 5.9 \% 、 10.3 \% 、 1.5 \%$, 可见冬季鄱阳湖水鸟 群落结构还是以冬候鸟为主 (表 2).

在 68 种鸟类中, IUCN 受胁鸟类 9 种, 包括极危物种白鹤和青头潜鸭; 濒危种东方白鹳、黑脸琵鹭和中华 秋沙鸭; 易危种白头鹤、白枕鹤、鸿雁 (A. cygnoides) 和小白额雁. 国家一级保护鸟类 5 种,包括东方白鹳、黑 鹳 (Ciconia nigra)、中华秋沙鸭、白头鹤、白鹤; 国家二级保护鸟类 6 种,包括白琵路 (Platalea leucorodia)、黑 脸琵路、小天鹅 (Cygnus columbianus)、白额雁 (A. albifrons)、灰鹤 ( G. grus)、白枕鹤; 江西省级保护鸟类 29 种. 属于《中华人民共和国政府和日本国政府保护候鸟及其栖息环境的协定》的鸟类有 48 种, 属于《中华人 民共和国政府和澳大利亚政府保护候鸟及其栖息环境的协定》的有 11 种, 列人《国家保护的有益的或者有 重要经济价值,科学研究价值的陆生野生动物名录》的有 54 种 (表 2).

\section{2 水鸟丰富度}

雁鸭类相对丰富度最高, 是鄱阳湖越冬水鸟的优势类群, 其次是衍形目鸟类. 在 2015 和 2016 年, 雁鸭类 水鸟分别为 432378 和 270103 只,各占当年水鸟总数的 $87.5 \%$ 和 $69.6 \%$; 鸭形目鸟类分别为 24713 和 51675 只,各占当年水鸟总数的 $5.0 \%$ 和 $13.3 \%$. 再次是鹳形目和鹤形目鸟类, 2015 和 2016 年冬季鹳形目鸟类分别 为 14068 和 19434 只, 分别占 $2.8 \%$ 和 $5.0 \%$, 鹤形目鸟类分别为 12877 和 5267 只, 各占 $2.6 \%$ 和 $1.4 \%$; 扸硒目 和鹈形目鸟类相对丰富度最低, 其中鸲鹰目鸟类 2015 年仅 2878 只, 占 $0.6 \%, 2016$ 年数量增加到 4465 只, 占 $1.2 \%$; 鹈形目仅有一个物种, 即普通扸鹚 (Phalacrocorax carbo), 2015 年记录到 7119 只, 占 $1.4 \%, 2016$ 年仅 2514 只,占 $0.6 \%$

雁形目鸟类: 雁类在两次调查中个体数量最多, 数量分别为 261580 和 217833 只, 分别占雁形目鸟类总 数的 $60.5 \%$ 和 $80.6 \% .2015$ 年冬季鸿雁、小天鹅和豆雁 (Anser fabalis) 是优势物种, 种群数量分别为 152918 、 65882 和 84002 只, 各占雁形目鸟类总数的 $35.4 \% 、 15.2 \%$ 和 $19.4 \%$. 虽然 2016 年的个体数量与 2015 年相比 差距较大, 但所占比例相当, 其种群数量分别为 86367 只、34559 只和 47853 只, 各占雁形目鸟类总数的 $32.0 \% 、 12.8 \%$ 和 $17.7 \%$ 。 
表 $22015-2016$ 年冬季鄱阳湖越冬水鸟物种组成和丰富度 $*$

Tab.2 The wintering water bird species and abundance in Poyang Lake in winter of 2015 and 2016

\begin{tabular}{|c|c|c|c|c|c|c|c|c|c|}
\hline & \multirow{2}{*}{ 中文名 } & \multirow{2}{*}{ 学名 } & \multicolumn{2}{|c|}{ 数量 } & \multirow{2}{*}{$\begin{array}{c}\text { 居留 } \\
\text { 型 }\end{array}$} & \multirow{2}{*}{$\begin{array}{l}\text { 区系 } \\
\text { 从属 }\end{array}$} & \multirow{2}{*}{$\begin{array}{l}\text { 保护 } \\
\text { 级别 }\end{array}$} & \multirow{2}{*}{ 中日 } & \multirow{2}{*}{ 中澳 三有 } \\
\hline & & & 2015 年 & 2016 年 & & & & & \\
\hline 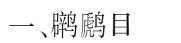 & \multicolumn{9}{|c|}{ PODICIPEDIFORMES } \\
\hline (一) 䴙片科 & \multicolumn{9}{|c|}{ Podicipedidae } \\
\hline 1 & 小鸲鸼 & Tachybaptus ruficollis & 1824 & 3050 & 留 & 广 & III & & V \\
\hline 2 & 凤头䲽䝞 & Podiceps cristatus & 1054 & 1415 & 冬 & 古 & III & V & $\checkmark$ \\
\hline 二、鹈形目 & \multicolumn{9}{|c|}{ PELECANIFORMES } \\
\hline (二) 鸹鹚科 & \multicolumn{9}{|c|}{ Phalacrocoracidae } \\
\hline 3 & 普通鸹鹚 & Phalacrocorax carbo & 7119 & 2514 & 夏 & 广 & III & & V \\
\hline 三、鹳形目 & \multicolumn{9}{|c|}{ CICONIIFORMES } \\
\hline (三)路科 & \multicolumn{9}{|c|}{ Ardeidae } \\
\hline 4 & 苍鹭 & Ardea cinerea & 1932 & 4236 & 留 & 东 & III & & V \\
\hline 5 & 白路 & Egretta garzetta & 3423 & 1595 & 夏 & 东 & III & & V \\
\hline 6 & 中白路 & Egretta intermedia & 0 & 48 & 夏 & 东 & & V & V \\
\hline 7 & 夜鹭 & Nycticorax nycticorax & 0 & 52 & 夏 & 广 & & V & V \\
\hline 8 & 绿路 & Butorides striata & 62 & 0 & 夏 & 广 & III & V & V \\
\hline (四) 鹳科 & \multicolumn{9}{|l|}{ Ciconiidae } \\
\hline 9 & \multicolumn{9}{|c|}{ 东方白鹳 $\quad$ Ciconia boyciana } \\
\hline 10 & 黑鹳 & Ciconia nigra & 1 & 23 & 冬 & 古 & I & V & \\
\hline (五)鲄科 & \multicolumn{9}{|c|}{ Threskiornithidae } \\
\hline 11 & 黑脸琵路 & Platalea minor & 0 & 3 & 旅 & 古 & II & V & \\
\hline 12 & 白琵鹭 & Platalea leucorodia & 3674 & 9597 & 冬 & 古 & II & V & \\
\hline 四、雁形目 & \multicolumn{9}{|c|}{ ANSERIFORMES } \\
\hline (六) 鸭科 & \multicolumn{9}{|c|}{ Anatidae } \\
\hline 13 & 小天鹅 & Cygnus columbianus & 65882 & 34559 & 冬 & 古 & II & V & \\
\hline 14 & 鸿雁 & Anser cygnoides & 152918 & 86367 & 冬 & 古 & III & V & V \\
\hline 15 & 豆雁 & Anser fabalis & 84002 & 47853 & 冬 & 古 & III & $\checkmark$ & V \\
\hline 16 & 小白额雁 & Anser erythropus & 0 & 637 & 冬 & 古 & III & V & V \\
\hline 17 & 白额雁 & Anser albifrons & 16109 & 18075 & 冬 & 古 & II & V & \\
\hline 18 & 灰雁 & Anser anser & 2397 & 6376 & 冬 & 古 & III & & V \\
\hline 19 & 黑雁 & Branta beernicla & 0 & 1 & 迷 & 东 & & & V \\
\hline 20 & 赤麻鸭 & Tadorna ferruginea & 1985 & 518 & 冬 & 古 & III & V & V \\
\hline 21 & 针尾鸭 & Anas acuta & 413 & 1036 & 冬 & 古 & III & V & V \\
\hline 22 & 绿翅鸭 & Anas crecca & 574 & 4200 & 冬 & 古 & III & V & V \\
\hline 23 & 罗纹鸭 & Anas falcata & 3949 & 1347 & 冬 & 古 & & $\checkmark$ & V \\
\hline 24 & 绿头鸭 & Anas platyrhynchos & 10637 & 1253 & 冬 & 古 & III & V & V \\
\hline 25 & 斑嘴鸭 & Anas poecilorhyncha & 15863 & 12016 & 留 & 古 & III & & V \\
\hline 26 & 花脸鸭 & Anas formosa & 8 & 76 & 冬 & 古 & III & V & V \\
\hline 27 & 赤膀鸭 & Anas strepera & 0 & 307 & 冬 & 广 & III & V & V \\
\hline 28 & 赤颈鸭 & Anas penelope & 39 & 759 & 冬 & 古 & III & V & V \\
\hline 29 & 红头潜鸭 & Aythya ferina & 2507 & 2557 & 冬 & 古 & III & V & V \\
\hline 30 & 青头潜鸭 & Aythya baeri & 0 & 40 & 冬 & 古 & III & V & V \\
\hline 31 & 白眼潜鸭 & Aythya nyroca & 88 & 10 & 冬 & 古 & & & V \\
\hline 32 & 翘鼻麻鸭 & Tadorna tadorna & 56 & 2 & 冬 & 古 & III & V & V \\
\hline 33 & 凤头潜鸭 & Aythya fuligula & 515 & 206 & 冬 & 古 & III & V & V \\
\hline 34 & 棉凫 & Nettapus coromandelianus & 30 & 0 & 夏 & 东 & III & & V \\
\hline 35 & 普通秋沙鸭 & Mergus merganser & 0 & 103 & 冬 & 古 & III & V & V \\
\hline
\end{tabular}


续表 2

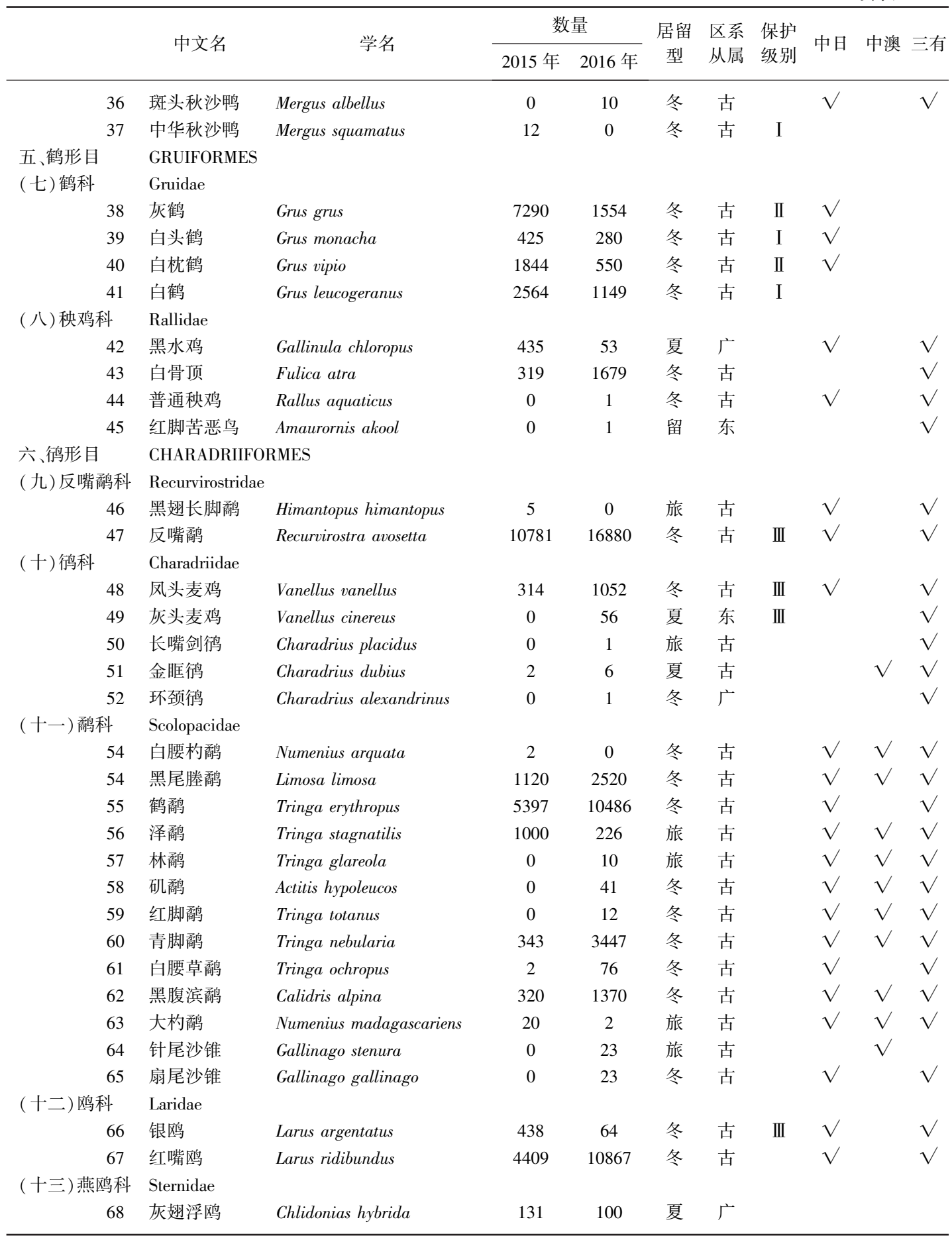

* 居留型:留表示留鸟、冬表示冬候鸟、夏表示夏侯鸟、旅表示旅鸟; 区系:古表示古北界、东表示东洋界、广表示广布种; 保护级别: I、II 分别表示国家 I 级、II 级保护鸟类, III 表示省级保护鸟类; IUCN 表示 IUCN 全球性物种濒危等级: CR 表 示极危, EN 表示濒危, VU 表示高危 (易危), LC 表示低危. 候鸟保护协定: 中澳表示《中华人民共和国政府和澳大利亚政 府保护候鸟及其栖息环境的协定》, 中日表示《中华人民共和国政府和日本国政府保护候鸟及其栖息环境的协定》; 三有 表示列人《国家保护的有益的或者有重要经济价值, 科学研究价值的陆生野生动物名录》的动物. 
彻形目鸟类: 2015 年反嘴璚科鸟类数量最多, 占衍形目鸟类总数量的 $40.9 \%$; 䂆科鸟类次之, 占 $31.1 \%$; 其次分别为鸥科鸟类、行科鸟类、燕鸥科鸟类,分别占该类群水鸟总数的 $24.6 \% 、 1.2 \%$ 和 $0.5 \%$. 2016 年璚科 鸟类数量最多, 占 $38.6 \%$; 反嘴璚科鸟类次之, 占 $35.7 \%$; 其次是鸥科、微科和燕鸥科鸟类, 分别占 $23.1 \%$ 、 $2.4 \%$ 和 $0.2 \%$. 反嘴䂆鸟 (Recurvirostra avosetta) 、鹤璚( Tringa erythropus) 和红嘴鸥 (Larus ridibundus) 在两次的调 查中均为优势物种, 在 2015 年其种群数量分别为 10781 、5397 和 4409 只,各占 $40.9 \% 、 20.5 \%$ 和 $16.7 \%$; 在 2016 年其种群数量分别为 $16880 、 10486$ 和 10867 只,各占行形目鸟类总数的 $35.7 \% 、 22.2 \%$ 和 $23.0 \%$.

鹳形目鸟类: 2015 年鹭科鸟类数量最多, 共 5417 只, 占鹳形目鸟类总数量的 $38.5 \%$; 鹳科鸟类 2 种即东 方白鹳和黑鹳共 4977 只, 占 $35.4 \%$; 睘科鸟类 1 种即白琵鹭 3674 只, 占 $26.1 \% .2016$ 年噮科鸟类多达 9600 只, 占 $49.4 \%$; 喝科鸟类共 5931 只, 与上一年数量相差不大, 占 $30.5 \%$; 鹳科鸟类 3903 只, 占 $20.1 \%$. 其中东 方白鹳、白路 (Egretta garzetta)、苍路 (Ardea cinerea) 和白琵鹗为优势物种.

鹤形目鸟类: 2015 年鹤科鸟类 4 种 12123 只, 占鹤形目鸟类总数量的 $94.1 \%$, 秧鸡科 2 种 754 只, 占 $5.9 \%$. 其中, 灰鹤、白鹤和白枕鹤是优势物种, 种群数量分别为 7290 、2564 和 1844 只, 各占鹤形目鸟类总数 的 $56.6 \%$ 、 $19.9 \%$ 和 $14.3 \%$. 与 2015 年相比, 2016 年鹤科鸟类 4 种仅 3533 只, 占 $67.1 \%$; 秧鸡科 4 种 1734 只， 占 32.9\%. 其中灰鹤、白鹤和白骨顶 (Fulica atra) 是优势物种, 种群数量分别为 $1554 、 1149$ 和 1679 只, 各占 $29.5 \% 、 21.8 \%$ 和 $31.9 \%$.

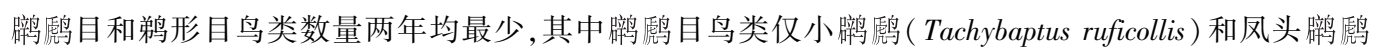
(Podiceps cristatus), 鹈形目鸟类仅有普通鸬鹚.

\section{3 水鸟多样性空间分异}

鄱阳湖各湿地区域越冬水鸟种类组成差异较大. 2015 年越冬期鄱阳湖国家级自然保护区水鸟种类最 多, 为 38 种; 其次是九江市湿地, 为 36 种; 南矶湿地自然保护区和南昌湿地分别有 24 和 17 种, 上饶湿地的 水鸟种类最少,为 14 种. 2016 年水鸟种类比 2015 年有所增长. 九江市鄱阳湖区水鸟种类最多, 为 54 种; 其 次是鄱阳湖自然保护区, 为 51 种; 南矶湿地保护区和上饶湿地分别有 30 种和 29 种, 南昌湿地的水鸟种类最 少, 为 21 种 (表 3). 在 2015 和 2016 年, 鄱阳湖国家级自然保护区内各类群水鸟均有分布, 分布最多的为雁 鸭类, 其次为天鹅、鹑璚类和鹭类, 包括鸿雁、豆雁、鹤璚、反嘴璚等; 鹳类和鹤类也主要分布在保护区内, 其 余片区分布很少甚至无分布; 九江湿地的优势种群为雁鸭类, 虽然 2016 年数量相比于 2015 年有所下降, 但 其仍然是调查区中雁鸭类分布最多的片区, 小天鹅、彻璚类和鸥类在 2016 年数量增加, 鹤类、鹳类依然很 少; 南矶湿地自然保护区在 2015 年分布最多的为鸭类, 其次为雁类, 2016 年雁类最多, 鸭类数量骤减, 鹭类 和鸭䂆鸟类稍有增长; 上饶湿地在 2015 年各类群中天鹅数量最多, 为 6602 只,2016 年天鹅、雁鸭类、鸭劀类均 有所增加; 南昌湿地在 2015 年冬季雁鸭类数量还较为可观, 但在 2016 年冬季各类群数量均减少.

表 32015 与 2016 年冬季鄱阳湖不同地区乌类多样性指数 *

Tab.3 Bird diversity indices in different areas of Poyang Lake in winter of 2015 and 2016

\begin{tabular}{|c|c|c|c|c|c|c|c|c|c|c|}
\hline \multirow{2}{*}{ 多样性指数 } & \multicolumn{2}{|c|}{ PY } & \multicolumn{2}{|c|}{ NJ } & \multicolumn{2}{|c|}{ JJ } & \multicolumn{2}{|c|}{ SR } & \multicolumn{2}{|c|}{$\mathrm{NC}$} \\
\hline & 2015 年 & 2016 年 & 2015 年 & 2016 年 & 2015 年 & 2016 年 & 2015 年 & 2016 年 & 2015 年 & 2016 年 \\
\hline 鸟种 $S$ & 38 & 51 & 24 & 30 & 36 & 54 & 14 & 29 & 17 & 21 \\
\hline 个体数 & 149362 & 120633 & 46942 & 42302 & 192468 & 155969 & 12258 & 61736 & 94653 & 7377 \\
\hline 多样性指数 $H^{\prime}$ & 3.97 & 3.75 & 1.98 & 2.45 & 2.48 & 3.35 & 2.25 & 2.80 & 2.00 & 3.19 \\
\hline 均匀度指数 $J$ & 0.75 & 0.66 & 0.43 & 0.50 & 0.48 & 0.58 & 0.59 & 0.58 & 0.49 & 0.73 \\
\hline 优势度指数 $D$ & 0.91 & 0.89 & 0.56 & 0.67 & 0.71 & 0.85 & 0.67 & 0.77 & 0.66 & 0.85 \\
\hline
\end{tabular}

* PY 表示鄱阳湖国家级自然保护区; NJ 表示南矶湿地国家级自然保护区; JJ 表示九江市鄱阳湖区湿地; SR 表示上饶市 鄱阳湖区湿地; $\mathrm{NC}$ 表示南昌市鄱阳湖区湿地.

从水鸟的空间分布来看,越冬水鸟主要集中在鄱阳湖自然保护区、九江湿地和南昌湿地. 2015 年越冬期 九江湿地、鄱阳湖国家级自然保护区和南昌湿地水鸟数量分别为 $192468 、 149362$ 和 94653 只, 分别占水鸟总 数的 $38.8 \% 、 30.1 \%$ 和 $19.1 \%$; 南矶湿地自然保护区和上饶湿地水鸟相对数量较少, 分别有 46942 和 12258 
只, 仅占 $9.5 \%$ 和 $2.5 \% .2016$ 年越冬水鸟主要集中在九江湿地和鄱阳湖自然保护区, 其次是上饶湿地和南矶 湿地国家级自然保护区, 数量分别为 $155969 、 120633 、 61736$ 和 42302 只, 占比为 $40.2 \% 、 31.1 \% 、 15.9 \%$ 和 $10.9 \%$. 南昌湿地水鸟最少, 仅 7377 只, 占 $1.9 \%$.

2015 和 2016 年鄱阳湖国家级自然保护区水鸟 Shannon-Wiener 多样性指数均为最高 (表 3), 分别是 $3.97 、 3.75$, 南矶湿地国家级自然保护区均为最低,分别是 $1.98 、 2.45 .2015$ 年鄱阳湖国家级自然保护区的 Peilou 均匀性指数最高, 为 $0.75,2016$ 年为南昌湿地最高, 0.73 ; 南矶湿地国家级自然保护区均为最低, 分别 为 $0.43 、 0.50$. 在 Simpson 优势度指数方面, 两年冬季均为鄱阳湖国家级自然保护区最高, 分别为 0.91 和 0.89 , 南矶湿地国家级自然保护区均最低,分别为 0.56 和 0.67 .

水鸟数量较多的湖泊包括鄱阳湖自然保护区的蚌湖、大湖池、沙湖和大汉湖,都昌县的黄金咀朱袍山区 域、大泟池、小河池、采阳圩堤外湖、高桥湖，以及南昌湿地的三湖. 在这些碟形湖中观察到的所有越冬鸟类 个体数量多达上万只, 既有数量上万的大群也有数量较少的小群. 在各调查区中数量超过 1 万只的记录点 分别是九江都昌县的小㑂池草洲、采阳圩堤外湖、黄金咀朱袍山区域、鄱阳湖自然保护区的大汉湖和南昌三 湖; 此外鄱阳湖自然保护区的象湖、中湖池、董家湖、小滩湖、蚌湖、沙湖等地区也有较多分布, 数量基本都达 上千只. 鹳形目鸟类主要分布在鄱阳湖自然保护区的沙湖、大汉湖、大湖池和南昌湿地等地,例如东方白鹳 2015 年冬季集中分布的地区有南昌湿地和鄱阳湖自然保护区, 其中数量最多的观测点是南昌县的三湖, 有 1852 只, 其次分别为大湖池、大汉湖和沙湖等. 鹤形目鸟类包括白鹤、白枕鹤、白头鹤和灰鹤, 主要集中分布 在鄱阳湖自然保护区的蛙湖、大汉湖和董家湖, 共青城的南湖, 都昌县的黄金咀朱袍山区域, 例如 2015 年冬 季白鹤、灰鹤在大汊湖分别分布有 2104 和 2724 只(表 4).

表 4 部分越冬水鸟集中分布的湖泊

Tab.4 Distribution of several species in important lakes

\begin{tabular}{|c|c|c|c|c|c|c|c|c|c|c|c|c|c|c|c|c|}
\hline \multirow[b]{2}{*}{ 湖泊 } & \multicolumn{2}{|c|}{ 白鹤 } & \multicolumn{2}{|c|}{ 白头鹤 } & \multicolumn{2}{|c|}{ 白枕鹤 } & \multicolumn{2}{|c|}{ 灰鹤 } & \multicolumn{2}{|c|}{ 小天鹅 } & \multicolumn{2}{|c|}{ 鸿雁 } & \multicolumn{2}{|c|}{ 东方白鹳 } & \multicolumn{2}{|c|}{ 白琵鹭 } \\
\hline & $\begin{array}{c}2015 \\
\text { 年 }\end{array}$ & $\begin{array}{c}2016 \\
\text { 年 }\end{array}$ & $\begin{array}{c}2015 \\
\text { 年 }\end{array}$ & $\begin{array}{c}2016 \\
\text { 年 }\end{array}$ & $\begin{array}{c}2015 \\
\text { 年 }\end{array}$ & $\begin{array}{c}2016 \\
\text { 年 }\end{array}$ & $\begin{array}{c}2015 \\
\text { 年 }\end{array}$ & $\begin{array}{c}2016 \\
\text { 年 }\end{array}$ & $\begin{array}{c}2015 \\
\text { 年 }\end{array}$ & $\begin{array}{c}2016 \\
\text { 年 }\end{array}$ & $\begin{array}{c}2015 \\
\text { 年 }\end{array}$ & $\begin{array}{c}2016 \\
\text { 年 }\end{array}$ & $\begin{array}{c}2015 \\
\text { 年 }\end{array}$ & $\begin{array}{c}2016 \\
\text { 年 }\end{array}$ & $\begin{array}{c}2015 \\
\text { 年 }\end{array}$ & $\begin{array}{c}2016 \\
\text { 年 }\end{array}$ \\
\hline 象湖 & 0 & 17 & 0 & 0 & 0 & 4 & 0 & 35 & 3010 & 0 & 3700 & 1135 & 0 & 23 & 0 & 215 \\
\hline 大湖池 & 8 & 115 & 26 & 156 & 9 & 26 & 0 & 2 & 0 & 172 & 0 & 191 & 759 & 2786 & 1124 & 3741 \\
\hline 中湖池 & 120 & 0 & 0 & 0 & 64 & 0 & 169 & 0 & 3063 & 0 & 3150 & 0 & 0 & 0 & 0 & 0 \\
\hline 蚌湖 & 23 & 3 & 21 & 42 & 726 & 262 & 195 & 42 & 8 & 0 & 2127 & 900 & 18 & 185 & 448 & 86 \\
\hline 沙湖 & 0 & 2 & 20 & 3 & 74 & 51 & 47 & 17 & 193 & 0 & 2410 & 500 & 517 & 171 & 337 & 320 \\
\hline 大汉湖 & 2104 & 6 & 354 & 6 & 831 & 25 & 2724 & 19 & 12090 & 0 & 14200 & 14230 & 728 & 2 & 0 & 0 \\
\hline 董家湖 & 154 & 0 & 0 & 12 & 0 & 6 & 0 & 0 & 2027 & 0 & 1220 & 0 & 270 & 36 & 0 & 187 \\
\hline 小滩湖 & 27 & 0 & 0 & 0 & 0 & 0 & 0 & 0 & 2950 & 0 & 1860 & 0 & 0 & 0 & 0 & 0 \\
\hline 黄金咀朱袍山区域 & 0 & 2 & 0 & 0 & 7 & 64 & 69 & 0 & 405 & 706 & 27416 & 21056 & 0 & 0 & 0 & 0 \\
\hline 大泟池 & 0 & 0 & 0 & 0 & 0 & 34 & 0 & 7 & 1315 & 481 & 55 & 85 & 0 & 0 & 0 & 0 \\
\hline 小泟池 & 0 & 0 & 0 & 0 & 0 & 0 & 0 & 0 & 150 & 74 & 8530 & 0 & 0 & 0 & 0 & 0 \\
\hline 香阳圩堤外湖 & 0 & 0 & 0 & 0 & 0 & 0 & 0 & 19 & 6750 & 457 & 20028 & 46 & 0 & 0 & 0 & 0 \\
\hline 高桥湖 & 0 & 0 & 0 & 0 & 0 & 0 & 0 & 0 & 0 & 0 & 0 & 11000 & 0 & 0 & 0 & 0 \\
\hline 大小莲子湖 & 0 & 6 & 0 & 0 & 0 & 0 & 0 & 132 & 1821 & 1074 & 1030 & 12170 & 0 & 45 & 0 & 722 \\
\hline 三湖 & 0 & 0 & 0 & 0 & 0 & 0 & 3000 & 0 & 15200 & 381 & 50320 & 785 & 1852 & 230 & 0 & 0 \\
\hline
\end{tabular}

\section{4 讨论}

\section{1 水鸟资源与物种组成}

近年来国内外研究人员在鄱阳湖区开展了大量的水鸟多样性研究,据统计,鄱阳湖区水鸟中冬候鸟最 多为 70 种, 但本研究在两年调查中仅记录到 46 种, 原因可能是: (1)不同的研究关于鄱阳湖区的定义不同, 有 些研究将鄱阳湖区定义为湖区 13 县市的范围, 既包括了鄱阳湖湿地, 也包括了周边的农田和森林, 本研究 区域限于鄱阳湖湿地范围内, 未包括周边的农田生态系统和森林生态系统. (2)有些水鸟在鄱阳湖区属于偶 
见种, 只有通过长期的监测才有可能发现; (3)关于鄱阳湖鸟类物种多样性的最多记录来自文献, 有一些曾在 鄱阳湖区有分布的鸟类物种已多年未见分布.

通过比较两年的调查结果, 发现雁鸭类和鿈劀类是鄱阳湖越冬水鸟的优势类群, 其中鸿雁、小天鹅、豆 雁和斑嘴鸭是优势物种,鹳形目和鹤形目鸟类比如东方白鹳、白鹤、白枕鹤等物种濒危等级较高, 但是相对 丰富度较低. 可见鄱阳湖虽然是珍稀濒危物种的重要越冬栖息地,但雁鸭类仍是鄱阳湖湿地越冬鸟类中的 优势种, 这一水鸟群落结构、优势种组成和吴英豪等 ${ }^{[17]}$ 的研究结果一致, 但各类群水鸟的数量却存在波动, 2015 年记录到水鸟 495683 只, 而 2016 年记录到 388017 只,水鸟数量的减少主要是由于雁鸭类、鹤类和鸥璚 类数量明显减少, 其中雁鸭类减少了近 13 万只, 鹤类数量约是 2015 年的 $1 / 3$. 考虑的原因可能是:一方面, 两年越冬期水位存在差异, 导致越冬水鸟栖息地和食物资源的可获得性发生较大变化, 从而使得越冬水鸟 数量存在较大差异 ${ }^{[11]}$; 另一方面,近几年来越来越多的水鸟选择在水稻田受食栖息,例如在鄱阳县大、小莲 子湖附近的水稻田有较多灰鹤, 金溪湖青岗湖附近的藕塘农田也有较多白鹤、小天鹅和鸥憰类 ${ }^{[18]}$, 这个现象 表明水鸟对人工湿地的利用开始加剧, 水鸟分布更加分散, 分布范围不仅是在湖区, 附近的农田可能也是其 栖息地,这也可能是导致在湖区调查记录的鸟类数量出现减少的原因.

在 2015 和 2016 年记录中,鹤类均主要集中在鄱阳湖自然保护区的大汉湖、中湖池、董家湖等,但其数量 波动较大, 2015 年冬季记录有 2564 只,多数分布在鄱阳湖自然保护区的大汉湖, 2016 年冬季记录 1149 只, 不同的是其在保护区内多个相邻子湖泊内分布均匀. 根据已有的研究报道显示 1998 年冬季至 2010 年冬季, 鄱阳湖区越冬白鹤种群平均大小为 3108 只 ${ }^{[19-20]}$, 这种情况虽不排除重复计数的可能,但总体而言, 自然湿 地中白鹤的数量近几年来明显减少, 藕塘和水稻田中的白鹤数量则急剧增加, 这值得进一步研究, 管理部门 函待制定并实施有效的保护.

\section{2 空间分布}

水鸟的聚集分布区相对比较稳定,2015 和 2016 年调查记录的越冬水鸟分布格局没有大的变化,主要集 中在鄱阳湖国家级自然保护区的蚌湖、象湖、大湖池、沙湖、寔豆湖和大汉湖等, 九江湿地的黄金咀朱袍山区 域、大泟池草洲、小㑂池草洲、采阳圩堤外湖等, 南矶湿地的茶湖、战备湖等, 这与 2011 年 $^{[4]}$ 和 2012 年 ${ }^{[21]}$ 鄱 阳湖大型水鸟分布调查结果一致. 越冬水鸟栖息的核心区域主要是鄱阳湖国家级自然保护区、九江湿地的 都昌自然保护区和南矶湿地自然保护区, 雁鸭类、天鹅、微璚类在这 3 个保护区内均有较多分布, 且雁鸭类 主要集中在鄱阳湖保护区和九江湿地,鹤形目鹤科和鹳形目鹳科集中分布在鄱阳湖自然保护区, 其余地区 分布很少甚至无分布.

本研究在两个越冬期的调查发现, 九江湿地水鸟数量与物种数均最多, 但是由于鸿雁和豆雁种群数量 巨大,2015 年冬季仅这两个物种就占该湿地数量的 $74.4 \%$, 导致九江湿地的水鸟 Shannon-Wiener 多样性指 数值与其他区域相比处于中等水平, 同样的情况还发生在上饶湿地. 就调查涉及到的两个国家级自然保护 区而言, 鄱阳湖国家级自然保护区的物种数和水鸟数量位居第一, 具有最高的多样性指数和均匀度指数; 南 矶湿地保护区多样性指数和均匀度指数最低. 这可能与候鸟食物资源和栖息地的可获得性有关, 鄱阳湖自 然保护区的苦草、苶子草和下江委陵菜等植物地下块茎食物资源丰富, 同时丰富的苔草也为雁形目鸟类提 供良好的受食场所,湖泊、岛屿、草洲和滩涂等各种各样的生境为各类群水鸟提供了良好的栖息场所,因此 其多样性指数和均匀度指数都较高; 南矶湿地相比较而言生境类型较少, 距离村庄城市较近, 放牧、火烧、捕 鱼等人为活动干扰性大, 因而导致其多样性指数和均匀度最低. 因此, 越冬水鸟在鄱阳湖各湿地片区的种类 组成和数量分布差异与各湖泊水位的高低、食物的分布、生境特点和人为活动活动强度等密切相关. 另外, 越冬水鸟由天然湿地向人工湿地的栖息地转移, 是否是由于鄱阳湖水位异常造成的适宜生境变化引起的, 还有待进一步探究.

\section{5 保护建议}

目前鄱阳湖区鸟类保护工作必须面对的问题仍然是社会经济发展与保护之间的矛盾,应当建立适当的 机制, 对破坏性的渔业生产方式、采砂、过度放牧等人为活动进行整顿, 加强教育宣传力度, 规范当地群众对 资源的利用模式, 以减少对鸟类栖息地的威胁. 鄱阳湖区虽已建立保护网络体系,但在保护区以外依旧存在 
保护空缺, 建议加强保护区外的越冬候鸟保护,制定管理方案恢复水鸟栖息地环境,同时鉴于越冬水鸟向藕 塘农田等人工湿地分散的现象, 也应加强人工湿地的管理保护, 实行对鄱阳湖天然湿地和人工湿地环境变 化的动态监测, 深人研究鄱阳湖气候、植被、水位、食物资源对水鸟种群的影响, 以便更加科学完善地制定保 护管理策略.

\section{6 参考文献}

[ 1 ] Xia SX, Liu GH, Yu XB et al. Assessment of wintering waterfowl habitat in Poyang Lake. J Lake Sci, 2015, 27(4) : 719726. DOI: 10.18307/2015.0421. [夏少霞, 刘观华, 于秀波等. 鄱阳湖越冬水鸟栖息地评价. 湖泊科学, 2015,27 (4) : 719-726. ]

[ 2 ] Cui P, Xia SX, Liu GH et al. Changes of overwintering waterfowl population in Poyang Lake. Sichuan Journal of Zoology, 2013, 32(2) : 292-296. [崔鹏, 夏少霞, 刘观华等. 鄱阳湖越冬水鸟种群变化动态. 四川动物, 2013, 32(2) : 292-296. ]

[ 3 ] Ji WT, Zeng NJ, Wang YB et al. Analysis on the waterbirds community survey of Poyang Lake in winter. Geographic Information Sciences, 2007, 13: 51-64.

[ 4 ] Zhu Q, Zhan YH, Liu GH et al. Survey on the number and distribution of waterfowls in Poyang Lake in winter of 2011. Jiangxi Forestry Science and Technology, 2012, (3): 1-9. [朱奇, 詹耀煌, 刘观华等. 2011 年冬鄱阳湖水鸟数量与分 布调查. 江西林业科技, 2012, (3) : 1-9.]

[ 5 ] Tu XB, Ma JH, Song YZ et al. Poyang Lake in winter wintering waterfowl resources and protection measures. Chinese Journal of Wildlife, 2000，(4): 6-7. [涂晓斌, 马建华, 宋玉赞等. 鄱阳湖越冬水禽资源现状及保护对策. 野生动物, 2000, (4):6-7.]

[ 6 ] Ji WT, Wu JD, Yi WS et al. Poyang Lake National Nature Reserve wading investigation report. Jiangxi Forestry Science and Technology, 2001，(2): 29-31. [纪伟涛, 吴建东, 易武生等. 鄱阳湖国家级自然保护区涉禽调查报告. 江西林 业科技, 2001, (2): 29-31.]

[ 7 ] Guo YR. Characteristics and ecological protection strategies of overwintering migratory bird population in Poyang Lake wetland [Dissertation]. Nanjing: Nanjing Forestry University, 2005. [ 郭英荣. 鄱阳湖湿地越冬候鸟群落特征与生态保护 对策 [学位论文]. 南京: 南京林业大学, 2005.]

[ 8 ] Zhong YX, Xiao JC. Study on the biodiversity conservation in Poyang Lake Nature Reserve. Inland Lakes and Poyang Lake Conference on Sustainable Development, 2005. [钟业喜, 肖加超. 鄱阳湖自然保护区生物多样性保护研究. 内陆湖 泊暨鄱阳湖可持续发展研讨会, 2005.]

[ 9 ] Huang P, Ouyang S, Ruan LZ et al. Biodiversity of summer bird community in Nanji Mountain Wetland Nature Reserve. Journal of Nanchang University: Nature Science, 2009, 33(6) : 585-590. [黄鹏, 欧阳珊, 阮禄章等. 南矶山湿地自然 保护区夏季鸟类群落生物多样性. 南昌大学学报: 理科版, 2009, 33(6) : 585-590.]

[10] Zhang Q, Li L, Wang YG et al. Has the Three-Gorges Dam made the Poyang Lake wetlands wetter and drier? Geophysical Research Letters, 2012, 39(20): L20402.1-L20402.7.

[11] Jia YF. Study on the effect of water level fluctuation on wintering cranes and other waterbirds in Poyang Lake [Dissertation]. Beijing: Beijing Forestry University, 2013. [贾亦飞. 水位波动对鄱阳湖越冬白鹤及其他水鸟的影响研究 [学 位论文]. 北京: 北京林业大学, 2013.]

[12] Huang Y, Li YK, Ji WT et al. Analysis of bird diversity and conservation status in Poyang Lake. Wetland Science, 2016, 14(3) : 311-327. [黄燕, 李言阔, 纪伟涛等. 鄱阳湖区乌类多样性及保护现状分析. 湿地科学, 2016, 14(3): 311-327.]

[13] Shan JH. Analysis of bird diversity and endangered bird population in Poyang Lake and their protection vacancies[ Dissertation]. Harbin: Northeast Forestry University, 2013. [单继红. 鄱阳湖鸟类多样性、濒危鸟类种群动态及其保护空缺 分析 [学位论文]. 哈尔滨: 东北林业大学, 2013.]

[14] Zheng GM ed. Chinese birds classification and distribution directory: Second edition. Beijing: Science Press, 2011. [郑光 美. 中国鸟类分类与分布名录: 第 2 版. 北京: 科学出版社, 2011.]

[15] Wang S ed. Red bird of China endangered species of birds. Beijing: Science Press, 1998. [汪松. 中国濒危动物红皮书 鸟类. 北京: 科学出版社, 1998.] 
[16] Mayenne J, Phillips K, Finch eds. China bird field manual. Changsha: Hunan Education Press, 2000. [约翰 - 马敬能, 卡伦・菲利普斯, 何芬奇. 中国鸟类野外手册. 长沙: 湖南教育出版社, 2000.]

[17] Wu YB, Ji WT eds. Jiangxi Poyang Lake National Nature Reserve. Beijing: China Forestry Publishing House, 2002. [吴 英豪, 纪伟涛. 江西鄱阳湖国家自然保护区研究. 北京: 中国林业出版社, 2002.]

[18] Shao MQ, Zhang CM, Dai NH et al. Time distribution and behavioral rhythm of overwintering Little Swans in Zhangtang habitat in Poyang Lake reclamation area. Chinese Journal of Ecology, 2018, 37(3): 817-822. [郡明勤, 张聪敏, 戴年 华等. 越冬小天鹅在鄱阳湖围垦区藕塘生境的时间分配与行为节律. 生态学杂志, 2018, 37(3):817-822.]

[19] Shan JH, Ma JZ, Li YK et al. Population and distribution of overwintering crane in Poyang Lake area in recent ten years. Zoological Research, 2012, 33(4) : 355-361. [单继红, 马建章, 李言阔等. 近十年来鄱阳湖区越冬白鹤种群数量与 分布. 动物学研究, 2012, 33(4): 355-361.]

[20] Li FS, Wu JD, Harris J et al. Number and distribution of wintering cranes in Poyang Lake in China in winter 2011-2012. Chinese Birds, 2012, 3(3) : 180-190. [李凤山, 吴建东, James HARRIS 等. 2011-2012 年冬季中国鄱阳湖越冬鹤 类的数量和分布. 中国鸟类, $2012,3(3): 180-190$.

[21] Liu GH, Jin JF, Li FS et al. Number and distribution of large wintering waterfowl in Poyang Lake in winter of 2012. South China Forestry Science, 2014, (1):39-43. [刘观华, 金杰锋, 李风山等. 2012 年冬季鄱阳湖大型越冬水鸟数量与 分布. 南方林业科学, 2014, (1) : 39-43.] 